\title{
The Added Value of Multislice CT Venography in Pre-Operative Assessment of the Deep Venous System of Both Lower Limbs; Correlation with the Doppler/US Findings
}

\author{
AMR A.H. GADALLA, M.D.*; HUSSEIN O. ELWAN, M.D.** and MOHAMED F. OSMAN, M.D.* \\ The Departments of Diagnostic \& Interventional Radiology* and Vascular Surgery**, Faculty of Medicine, Cairo University
}

\begin{abstract}
Background: Deep venous thrombosis is very common disease affecting the public health, so proper assessment and treatment improve the quality of patient's life. In addition DVT may cause pulmonary arterial thrombo-embolism.

Aims of the Study: To assess the value of CT venography in detailed assessment of the lower extremities deep venous system in comparison with the Doppler US findings for patients with swollen limbs referred from vascular clinics.

Patients and Methods: The study was carried over sixty patients (19 males and 41 females, age range 21-56 year old) from November 2016 to December 2017. Detailed evaluation of all examined patients was done using Doppler/US by experienced sonologist and multislice CT venography with calculation of the body mass index for each patient.

Results: Sixty patients (19 males and 41 females, age range 21-56 year old), body mass index range (20-34), Doppler findings showed that 54 patients were free of deep venous thrombosis and 6 patients with chronic deep venous thrombosis. However, multislice CT venography showed that 48 patients were free of deep venous thrombosis and 12 patients with chronic deep venous thrombosis. Also according to these results patients are classified as primary and secondary varicose veins.

Conclusion: Based on our results, multislice CT venography is a non operator dependant technique adding great clinical value in assessment of the patency and detailed delineation of the deep venous system, especially the abdominal and pelvic veins.
\end{abstract}

Key Words: CT venography-Doppler -DVT.

\section{Introduction}

DOPPLER/US is the most common imaging modality for evaluation of the venous system in the lower limbs because its availability, simplicity and safety. DVT of the lower extremities may be silent

Correspondence to: Dr. Amr A.H. Gadalla, The Department of Diagnostic \& Interventional Radiology, Faculty of Medicine, Cairo University or symptomatic. On doing US, the thrombosed vein appeared either hypo, iso or hyperechoic as well as the presence of free floating thrombus tail can be determined [1]. CT venography allows proper anatomical delineation of the veins and its tributaries [2]. Also the CT venography of the lower extremity veins has been used for many reasons, including; determination the site of venous perforators and traumatic venous injuries [3]. However, some limitations regarding the use of ionizing radiation and associated complications (possible extravasation and allergic reaction) are still present [4].

\section{Patients and Methods}

\section{Inclusion criteria:}

The study was done over sixty patients with swollen limbs (19 males and 41 females, range 2156 year old) from November 2016 to December 2017. The patients were referred from Kasr AlAiny Vascular Surgery Clinics to the Radiology Department and private center. Detailed assessment of the deep venous system of both lower limbs after obtaining informed consent was done by Doppler US and CT venography as well as calculation of the body mass index for each patient. The study is Institutional Board Review (IBR) approved.

\section{Exclusion criteria:}

- Patients refusing participation in the study.

- Patients with high renal functions or allergy to contrast media.

\section{Equipment:}

The study was performed on LOGIQ* S8US machine and Philips ICT 256 multislice scanners. 


\section{Techniques:}

Calculation of the body mass index was done in every patient by following this equation:

$$
\frac{\text { Weight (in kg) }}{\text { Height }^{2}\left(\text { in }^{2}\right. \text { ) }}
$$

The normal range of this measurement is 20.1 to 25.0 for men and 18.7 to 23.8 for women.

\section{DOPPLER US Technique:}

Every patient was examined by qualified sonologist using the linear $(9-12 \mathrm{MHz})$ and convex transducers $(3.5-5 \mathrm{MHz})$. The patient is examined in recumbent position and scanned from the umbilical region down to the ankle joints using ultrasonic gel, including the IVC (infra renal, renal, hepatic and suprahepatic segments), common iliac, external iliac, internal iliac, common femoral, superficial femoral, deep femoral and popliteal veins as well as the anterior tibial, posterior tibial and peroneal venae commitants. Gastrocnaemius and soleal calf veins are also examined.

\section{Duplex image interpretation:}

Normal Duplex appearance of the veins Fig. (1):

$B$-mode:

- Vein diameter more than the adjacent artery.

- Very thin wall (hardly seen).

- Complete resolution on compression.

Color:

- Completely filled by color with no filling defects.

Pulsed wave:

- Monopahsic with respiratory phasicisty. Loss of normal phasicisty means obstruction.

- On doing Valsalva's maneuver: Complete cessation of the flow.

In case of DVT:

I-Acute: Distended and hypoechoic (compared to the muscle).

II- Subacute: Isoechoic (due to clot retraction).

\section{III- Chronic:}

- Reduced vein caliber with echogenic thrombus remnants, intra-luminal synechia and venous reflux as well as the degree of recanalization Fig. (2).

- Peripheral veins easy to recanalize.

- Central veins are difficult due to the well developed collateral venous circulation.

\section{CT venography Technique:}

- The MDCT scans were performed on Philips iCT 256 multislice scanners.

- A tourniquet was applied over the distal legs. Proper sterilization of the feet was done followed by intra-venous cannulation.

- After obtaining the scout images from the diaphragm to the feet, CT venography was performed using a detector collimation of 2-128 rows $\mathrm{X} 0.625-1.25 \mathrm{~mm}$, a table feed of $24 \mathrm{~mm}, 80-140 \mathrm{kV}$, 10-1000 effective mAs, a rotation speed of 10,800 rpm and with $100 \mathrm{~mL}$ of contrast media (Omnipaque) at a flow of $4 \mathrm{~mL} / \mathrm{s}$, and the contrast media was administered by an automated injector through the applied venous cannulas taking multiple consequent phases.

- We used thin 1-mm axial images (source images). Several advanced reconstruction techniques used for accurate interpretation, including 2D multiplanar reformatting, Maximum Intensity Projection (MIP), curved planar reformatting, and 3D reconstruction.

\section{CT venography images analysis:}

- The quality of the CT venographic images is assessed by looking for the degree of venous enhancement in comparison with the surrounding soft tissue density. The targeted veins should be homogenously opacified with no intra-luminal filling defects.

- Detailed anatomical delineation of the deep venous system of both lower limbs is noted starting from the IVC down to both ankles Fig. (3).

- Exact site and extensions of the DVT are reported as well as the collateral venous circulation.

\section{III- Statistical analysis:}

Pre-coded data was analyzed through the Statistical Package of Social Science Software program, Version 23 (IBM SPSS Statistics for Windows, Version 23.0. Armonk, NY: IBM Corp.). Data was summarized as mean and Standard Deviation (SD) for quantitative variables and frequency and percentage for qualitative ones. Comparison between groups was performed using independent sample $t$-test and Mann Whitney test for quantitative variables and Chi square and Fisher's exact test for qualitative ones. Receiver Operating Characteristics (ROC) curve analysis was conducted to explore the predictive ability for Endoleak. $p$ values less than or equal to 0.05 were considered statistically significant. 

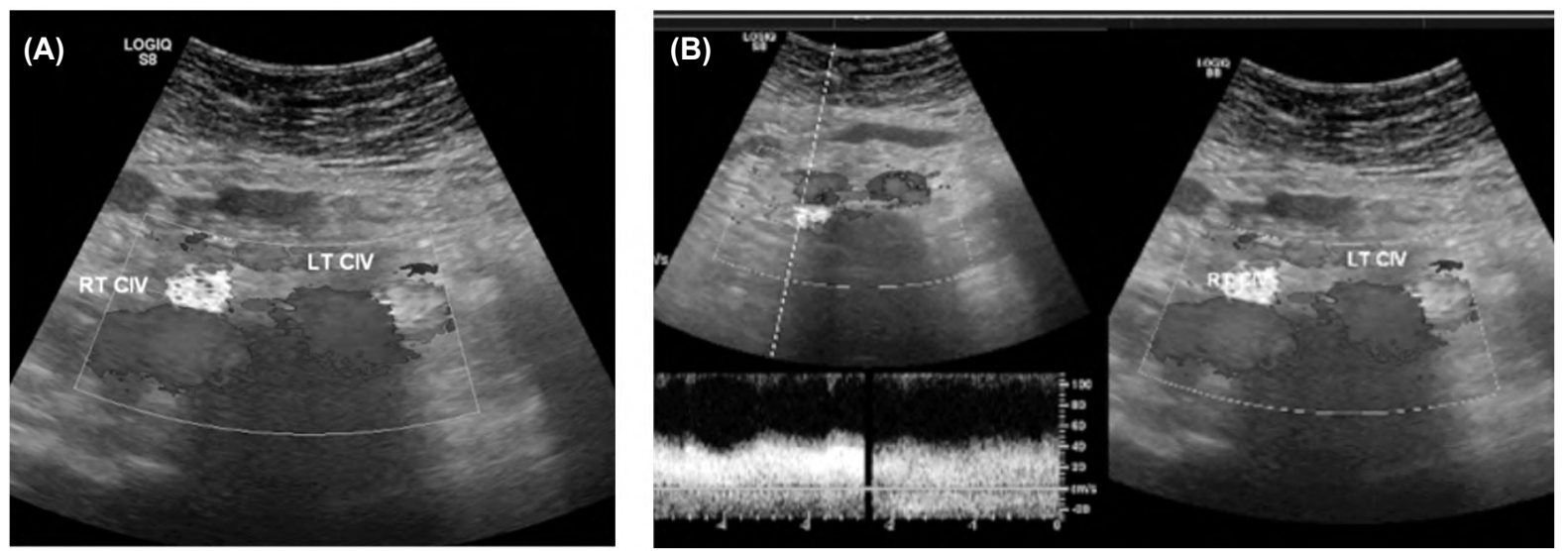

Fig. (1A,B): Normal color Doppler and monophasic venous flow of the iliac veins in 34 year old male with body mass index of 22. No DVT was noted through the examination.
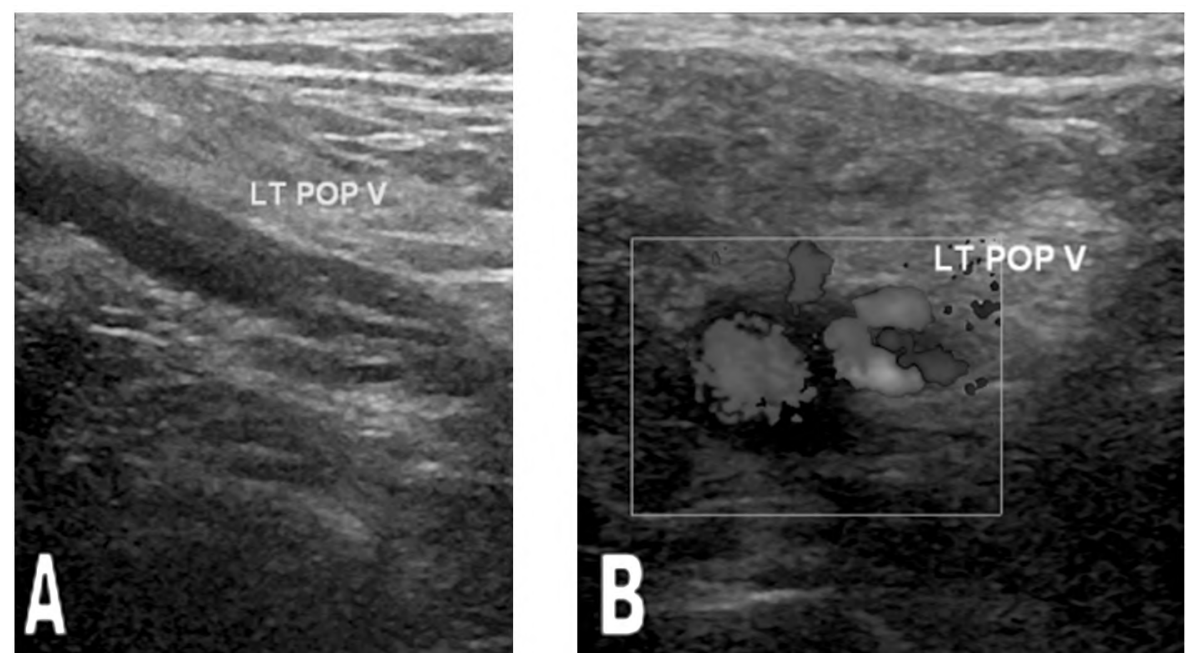

Fig. (2A,B): Chronic significantly recanalized DVT of the popliteal vein and intra-luminal synechia (arrowed) in 40 year old male with body mass index of 27.
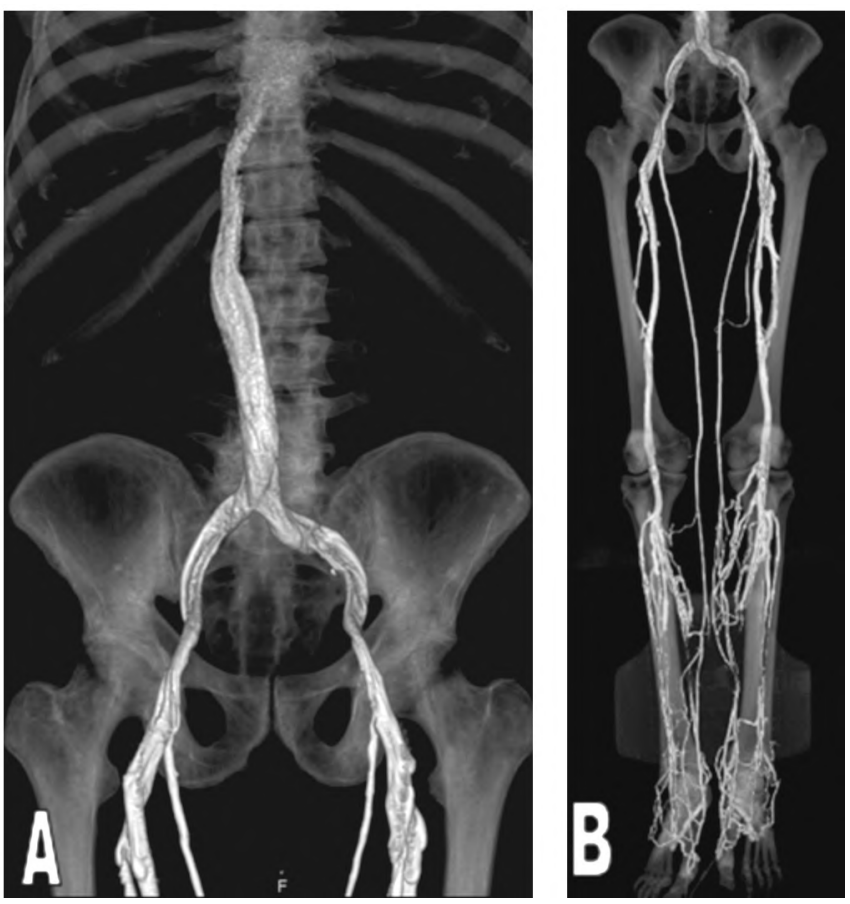

Fig. (3): Normal 3D CT venography images in 29 female patients with body mass index of 25 . 


\section{Results}

This cross sectional study carried on 60 patients (19 males and 41 females); the mean age for all patients was 38.5 years (age range, 21-56 years). The body mass index range was 20-34. The Doppler /US revealed that 6 patients had DVT and 54 patients were free, however CT venography revealed that 12 of patients had DVT where 48 patents were free, according to that patients were classified as 1ry and 2ry varicose veins. The site of DVT detected as follows; 3 at the IVC, 3 at the iliac, 3 at the femoral and 3 at the popliteal veins (Table 1).

Table (1): Description of all study parameters.

\begin{tabular}{|c|c|}
\hline & Description $(n=60)$ \\
\hline \multicolumn{2}{|l|}{ Age: } \\
\hline Range & $21-56$ \\
\hline Mean \pm SD & $38.5 \pm 8.3$ \\
\hline \multicolumn{2}{|l|}{ Sexn, $(\%):$} \\
\hline Male & $19(31.7)$ \\
\hline Female & $41(68.3)$ \\
\hline \multicolumn{2}{|l|}{ BMI: } \\
\hline Range & $20-34$ \\
\hline Mean \pm SD & $26.1 \pm 3.3$ \\
\hline \multicolumn{2}{|c|}{ Doppler findingn, (\%): } \\
\hline$+\mathrm{VE}$ & $6 \quad(10)$ \\
\hline$-\mathrm{VE}$ & $54(90)$ \\
\hline \multicolumn{2}{|c|}{ CTV findingn, (\%): } \\
\hline$+\mathrm{VE}$ & $12(20)$ \\
\hline$-\mathrm{VE}$ & $48(80)$ \\
\hline \multicolumn{2}{|c|}{ Type of VVn, (\%): } \\
\hline 1ry & $48(80)$ \\
\hline 2ry & $12(20)$ \\
\hline \multicolumn{2}{|l|}{ DVT siten, (\%): } \\
\hline Iliac & $3(5)$ \\
\hline IVC & $3(5)$ \\
\hline Femoral & $3(5)$ \\
\hline Popliteal & $3(5)$ \\
\hline
\end{tabular}

Positivity of CT venography for DVT was significantly associated with older age, larger BMI and male gender (Table 2).

In comparison of the CT venography with the Doppler finding showed that positivity of CT venography (DVT) was significantly associated with Positivity of Doppler (Table 3). However, validity measures of Doppler versus CT venography showed $50 \%$ sensitivity, $100 \%$ specificity, Positive Predictive Value (PPV) of 100\%, Negative Predictive Value (NPV) of $88.9 \%$, accuracy of $90 \%$ (Table 4).

Table (2): Factors determining CTV positivity.

\begin{tabular}{lccc}
\hline & \multicolumn{2}{c}{ CTV finding } & $\begin{array}{c}p \text { - } \\
\text { value }\end{array}$ \\
\cline { 2 - 3 } & $+\mathrm{VE}(\mathrm{n}=12)$ & $-\mathrm{VE}(\mathrm{n}=48)$ & 0.005 \\
\hline Age & $44.4 \pm 7.2$ & $37.0 \pm 8.0$ & \\
Sex: & & & 0.039 \\
$\quad$ Male & $7(58.3)$ & $12(25)$ & \\
Female & $5(41.7)$ & $36(36)$ & $<0.001$ \\
BMI & $30.4 \pm 2.8$ & $25.0 \pm 2.3$ & \\
\hline
\end{tabular}

Positivity of CT venography (DVT) was significantly associated with older age, larger BMI and male gender.

Table (3): Factors determining Doppler positivity.

\begin{tabular}{lccr}
\hline & \multicolumn{2}{c}{ Doppler finding } & $\begin{array}{c}p \text { - } \\
\text { value }\end{array}$ \\
\cline { 2 - 3 } & $+\mathrm{VE}(\mathrm{n}=6)$ & $-\mathrm{VE}(\mathrm{n}=54)$ & \\
\hline Age & $50.5 \pm 4.0$ & $37.2 \pm 7.6$ & 0.001 \\
Sex: & & & \\
$\quad$ Male & $5(83.3)$ & $14(25.9)$ & 0.010 \\
Female & $1(16.7)$ & $40(74.1)$ & \\
BMI & $28.0 \pm 1.8$ & $25.9 \pm 3.3$ & 0.043 \\
\hline
\end{tabular}

Positivity of Doppler was significantly associated with older age, larger BMI and male gender.

Table (4): CT venography versus Doppler findings.

\begin{tabular}{lccc}
\hline & \multicolumn{2}{c}{ CTV finding } & $\begin{array}{c}p- \\
\text { value }\end{array}$ \\
\cline { 1 - 2 } & $+\mathrm{VE}(\mathrm{n}=12)$ & $-\mathrm{VE}(\mathrm{n}=48)$ & \\
\hline $\begin{array}{c}\text { Doppler finding: } \\
\text { +VE }\end{array}$ & $6(50)$ & $0(0)$ & \\
-VE & $6(50)$ & $48(100)$ & \\
\hline
\end{tabular}

Positivity of CT venography (DVT) was significantly associated with Positivity of Doppler.

6 of patients were negative at the Doppler/US and showing the higher body mass index, however the CT venography revealed abdomino-pelvic chronic DVT and venous collateralization Figs. $(4,5)$.

Table (5): Validity measures of Doppler versus CT venography.

\begin{tabular}{lcccc}
\hline Sensitivity & Specificity & PPV & NPV & Accuracy \\
\hline $50 \%$ & $100 \%$ & $100 \%$ & $88.9 \%$ & $90 \%$ \\
\hline
\end{tabular}




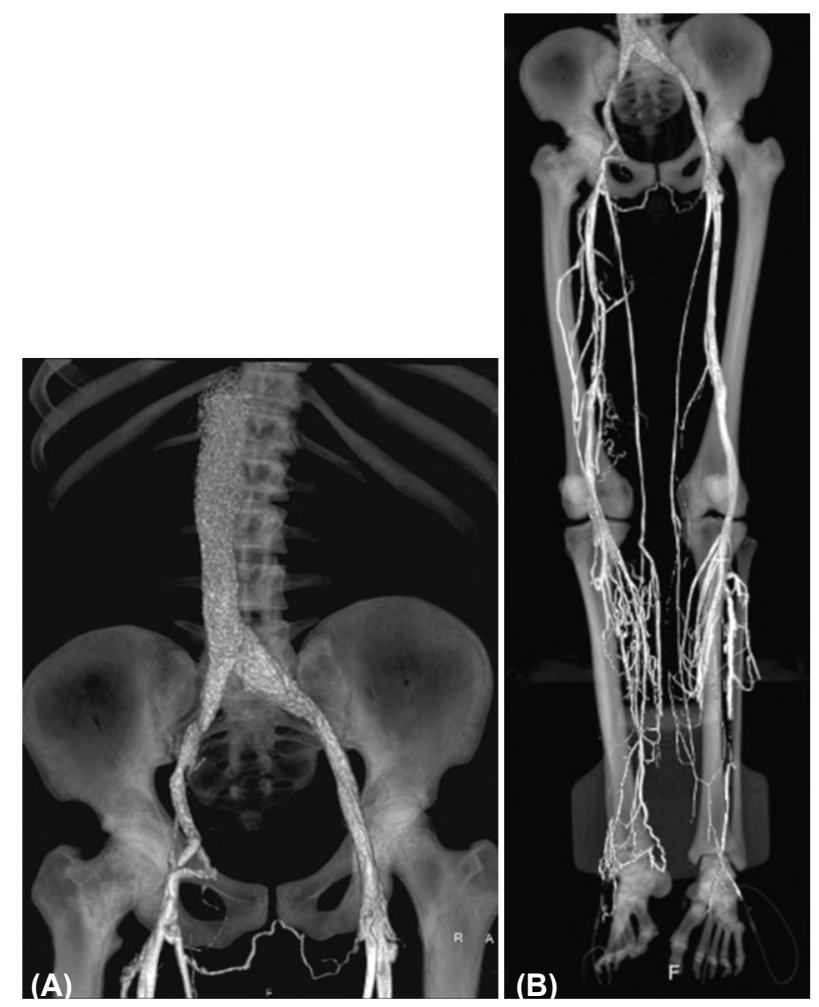

Fig. (4): 36 year old male with morbid obesity, Doppler/US revealed no DVT but the CT venography images revealed chronic recanalized DVT of the right common iliac and external iliac veins evident by reduced veins caliber compared to the left side with prominent venous collaterals crossing the groin.

\section{Discussion}

Venous duplex had been used as the first choice imaging tool in the diagnosis of DVT for clinically suspected patients because its availability, simplicity and safety [5].

Since the development of multidetector CT, the diagnostic accuracy of CT venography to detect DVT in the lower extremities was reported to be comparable to Doppler Sonography. These findings were mainly based on the significant difference in contrast attenuation value between the deep vein and its surrounding soft tissue density [6]. In the past, conventional venography has been the standard technique for diagnosing DVT. However, this technique is time-consuming and invasive. Therefore, conventional venography is seldom used nowadays [7]

Our study showed that CT venography might detect DVTs which were not detected by US in preoperative assessment of patients with swollen limbs. The incidence of DVT in the study was $20 \%$ and the incidence of IVC and iliac thrombosis was

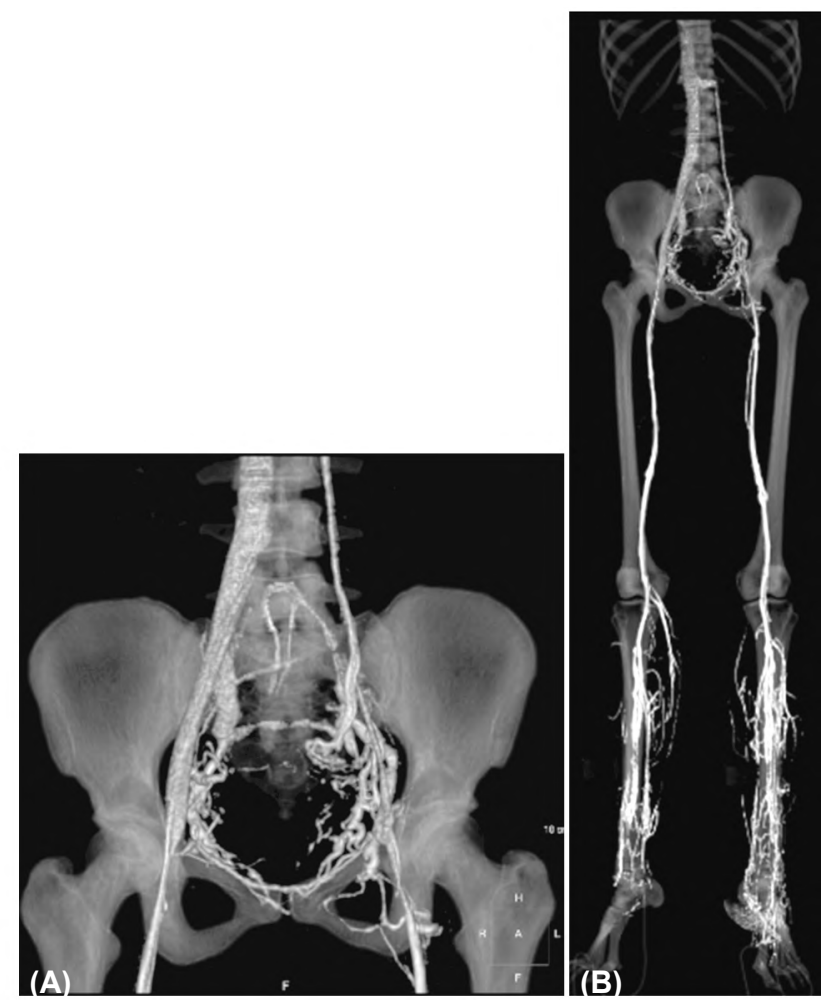

Fig. (5): 40 year old male with morbid obesity, Doppler/US revealed no DVT and one of the prominent venous collaterals misinterpreted as patent iliac veins but the CT venography images revealed chronic partially recanalized DVT of the left common iliac and external iliac veins evident by reduced veins caliber compared to the right side with pelvic venous collaterals crossing the groin.

$10 \%$, where they are missed by Doppler US due to morbid obesity and partial recanalization of the involved veins which misinterpreted as patent veins. The incidence of femoral and popliteal thrombosis was $10 \%$. There was no difference between the Doppler US findings and CT venography in detection of deep venous thrombosis below the groin. The study done by Tamura K et al., 2014 over 26 men and 46 women; mean age 65.2 years; age range, $37-81$ years, reported that the incidence of DVT was $2.6 \%$ and the incidence of iliac vein thrombosis was $4.2 \%$.

Sonographic evaluation of the calf veins was subjective depending on the operator's experience, as the DVTs seated in the gastrocnaemius and soleal veins were easily overlooked. For those reasons, it was reported that Duplex ultrasound has a low sensitivity [8]. In our study the sensitivity of Doppler US was 50\% compared to the CT venography, however it showed $100 \%$ specificity, $100 \%$ positive predictive value, $88.9 \%$ negative predictive value and $90 \%$ accuracy. 
Potential pitfalls of US imaging for DVT include duplication of the femoral vein, which is a common variety in many individuals, so if DVT is present in only one vein, US may be falsely negative if the patent vein is seen. The lower limb in this case is not grossly swollen because venous drainage occurs through the patent femoral vein which makes deceiving scenario [9].

Also, the IVC and iliac veins are challenging for routine evaluation with US because which may be limited by morbid obesity and improper colonic preparation. In addition, correctly recognizing chronic DVT and acute superimposed on chronic DVT is difficult [10]

Multidetector CT venography, with corresponding multiplanar reformatting images, can be performed to provide detailed information in selected patients (eg, those with ilio-femoral DVT) or in patients with incompetent perforators [11]. Volumetric CT venography revealed anatomic abnormalities (particularly extrinsic compression of the left common iliac vein by the right common iliac artery), we use such acquisitions for occasional problem solving after a non conclusive US [12]

Although the added value of CT venography compared to Doppler study in our study, limitations regarding the contrast administration and ionizing radiation were also noted.

\section{Conclusion:}

Based on our results, multislice CT venography is a non operator dependant technique adding great clinical value in assessment of the patency and detailed delineation of the deep venous system, especially the abdominal and pelvic veins.

\section{Acknowledgment:}

Our sincere thanks to all our professors and colleagues in the Radiology and Vascular Surgery Departments, Faculty of Medicine, Cairo University for their support.

\section{References}

1- SCHWARTZ T., HINGORANI A., ASCHER E., et al.: Pulmonary embolism without deep venous thrombosis. Ann. Vasc. Surg., 26: 973-6, 2012.
2- BALDT M.M., ZONTSICH T., STUMPfIEN A., FLEISCHMANN D., SCHNEIDER B., MINAR E., et al.: Deep venousthrombosis of the lower extremity: EffiCacy of spiralCT venography compared with conventional venography in diagnosis. Radiology, 200: 423-8, 1996.

3- THOMAS S.M., GOODACRE S.W., SAMPSON F.C., et al.: Diagnostic value of CT for deep vein thrombosis: Results of a systematic review and meta-analysis. Clin. Radiol., 63: 299-304, 2008.

4- BETTMANN M.A., ROBBINS A., BRAUN S.D., et al.: Contrast venography of the leg: Diagnostic efficacy, tolerance, and complication rates with ionic and nonionic contrast media. Radiology, 165: 113-6, 1987.

5- TAMURA K. and NAKAHARA H.: MR Venography for the Assessment of Deep Vein Thrombosis in Lower Extremities with Varicose Veins. Annals of vascular Diseases, 7 (4): 399-403, 2014.

6- BEGEMANN P.G.C., BONACKER M., KEMPER J., GUTHOFF A.E., HAHN K.E., STEINER P., et al.: Evaluation of the deep venous system in patients with suspected pulmonary embolism with multidetector CT: A prospective study in comparison to Doppler sonography. J. Comput. Assist. Tomogr., 27: 399-409, 2003.

7- HUISMAN M.V. and KLOK F.A.: Diagnostic management of acute deep vein thrombosis and pulmonary embolism. J. Thromb. Haemost., 11: 412-22, 2013.

8- ESKANDARI M.K., SUGIMOTO H., RICHARDSON T., WEBSTER M.W. and MAKAROUN M.S.: Is colorflow duplex a good diagnostic test for detection of isolated calf vein thrombosis in high-risk patients. Angiology, 51: 705-10, 2000

9- GARY T., STEIDL K., BELAJ K., et al.: Unusual deep venous thrombosis sites: Magnetic resonance venography in patients with negative compression ultrasound and symptomatic pulmonary embolism. Phlebology, Nov. 30 (epub), 2012.

10- JOHNSON S.A., STEVENS S.M., WOLLER S.C., et al.: Risk of deep vein thrombosis following a single negative whole-leg compression ultrasound: A systematic review and meta-analysis. J.A.M.A., 303: 438-45, 2010.

11- UHL J.F.: Three-dimensional modeling of the venous system by direct multislice helical computed tomography venography: Technique, indications, and results. Phlebology, 27: 270-88, 2012.

12- ZHU, MEIHUA SHI, WAN-YIN M.D., Ph.D.; WANG, LI-WEI M.D., Ph.D.; WANG, SHAO-JUAN M.D.; YIN, XIN-DAO M.D., Ph.D. and GU, JIAN-PING M.D.: Combined Direct and Indirect CT Venography (Combined CTV) in Detecting Lower Extremity Deep Vein Thrombosis. Medicine: March 2016-Volume 95-Issue 11-p e3 010doi: 10.1097/MD. 


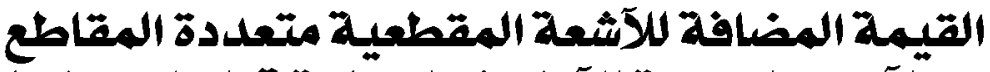

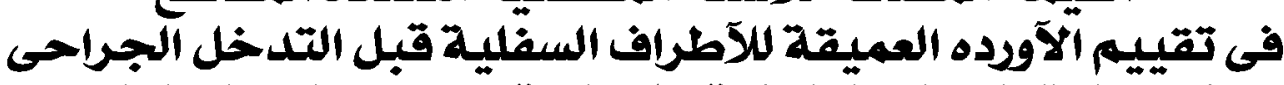

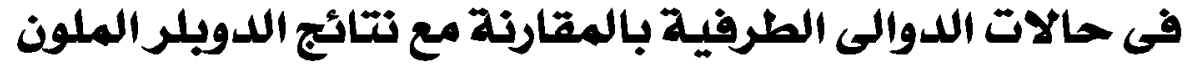

التخثر الميدى العميق من الآمراض الثائعة جدا التى ثئثر على الصحة العامة، لذلك التقييم والعلاج السليم يساعد بشكل كبير على تصسين نوعية حياة المريض.

الآهداف: لتحديد لود الآشعة المقطعية متعددة المقاطع فى تقييم الآودده العميقة للآطراف السفلية بالمقارنة مع نتائج الدوبلر الملون فى المي حالات تومث الطرف السفلي. الطرق: آجريت الدراسة على ستين مريضا (تسعة عشر ذكو وواحد وآربعون إناث، الفئة العمرية من واحل وعشرون حتى ستة وخمسون

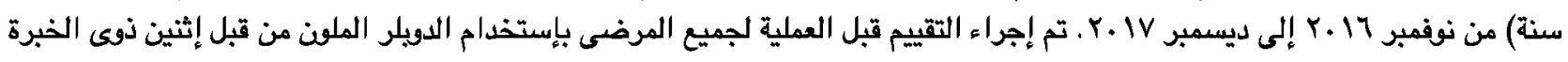
والآثعة المقطعية متعددة المقاطع مع صساب مؤثثر كثلة الجسم لكل مريض.

النتائج: ستون مريضا (تسعة عشر ذكو وقاحل وآريعن إناث، الفئة العمرية من واحل وعشرون حتى ستّة وخمسون سنة)، مؤثنر كتلة

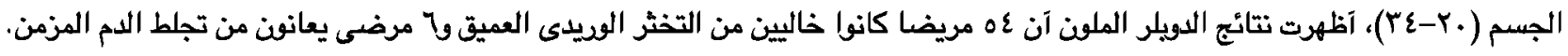

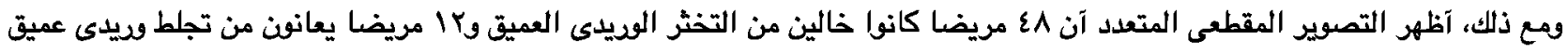

